\title{
EFFECTS OF TEACHING GEOMETRY USING MOBILE APP INSTRUCTIONAL TECHNIQUES ON SECONDARY SCHOOL STUDENTS' ACADEMIC ACHIEVEMENT IN BAYELSA STATE
}

\author{
Charles-Owaba, Tekenate \& Prof M J Ahiakwo \\ Department of Science Education, \\ River State University, Port Harcourt \\ Email: charlesOwabat@gmail.com
}

\begin{abstract}
The study investigated the effect of teaching geometry using mobile application instructional technique on senior secondary students' achievement in Bayelsa State, Nigeria. A quasi-experimental, pre-test, posttest, non-equivalent control group design was used in the study. All the mathematics students in the 3 federal unity schools formed the population of the study. One hundred and seventy nine (179) SS2 students from the two co-educational federal unity schools formed the sample of the study. Intact classes were assigned by flipping of coin to either experimental or control group; and separately taught by their regular mathematics teachers who had earlier been trained for the purpose. All the groups were pre and post-tested. Geometry Achievement Test (GAT) containing forty (40) multiple choice items was used as instrument for both the control and experimental groups. Six research questions and six research hypotheses guided the study. Mean and standard deviation were used to answer the research questions, while Analysis of Covariance (ANCOVA) was used to test the hypotheses at .05 levels of significance. The result of the study showed that: students that were taught with mobile app instructional technique had a higher achievement and interest scores than those taught with lecture method; it also indicated that there was no significant difference in the mean achievement and interest scores of male and female, as well as arts and science students taught geometry using mobile app instructional technique. Among such, it was recommended that since mobile app instructional technique enhances students' achievement and interest; it should be implemented in the teaching and learning of geometry and mathematics in Nigerian secondary schools and government and other stakeholders should ensure that teachers are trained adequately to enable them utilize mobile devices for teaching and learning purpose.
\end{abstract}

\section{INTRODUCTION}

Mathematics in general is linked with the development of any nation in the world. Mathematics as a discipline opens and shuts more doors for men and women than any other content area. Whether it is in business, science, engineering or technology, it is tremendously important that a person be well-armed with mathematics if they are going to have options in their lives (CharlesOwaba, 2018). Mathematics represents the superb and sublime product of reason as well as the upper limits of what one hopes to attain in all rational domain. Adenegan (2012) described mathematics as a model of thinking, for developing scientific structure, for drawing conclusions and for problem-solving. The supremacy of mathematics over other subjects is extolled by the 
National Policy on Education (NPE, 2014), when it stated that mathematics should be made a core subject in the primary and secondary education levels. The policy strongly emphasizes an effective teaching and learning of subject through the use of variety of strategies and this has consistently generated interest amongst scholars over the years.

Geometry is one of the most important branches of mathematics and it is concerned with the properties and relationships of lines, angles, curves, shapes, etc. The word geometry comes from two ancient Greek words, one meaning earth and the other meaning measure. Keith (2017) defined geometry as the branch of mathematics that exploits visual intuition (the most dominant of our senses) to remember theorems, understand proof, inspire conjecture, perceive reality and give global insight. He further asserts that these skills are transferable and are needed in all other branches of mathematics. In another vein, Sumzuma (2017) refers to geometry as that which helps us to acquire abilities such as making new discoveries, analyzing problems and making connections between mathematics and real life situations.

Throughout history, geometry has had a great importance in peoples' lives, originating with the need of human beings to specify quantities, to measure figures, land and earth and make maps. In other to represent and solve problems in survey and geo-informatics, sound geometry knowledge is necessary. Geometry is also used in other disciplines such as science of light (optics), geography (map design), music (note pattern design), art (model design), construction, and architecture, gardening and traffic signs. Artists, builders, draftsmen, masons, machinist, structural engineers and writers all make use of geometry daily.

The elements of geometry form an integral part of the mathematics and further mathematics curriculum. The teaching and learning of geometry starts from the primary school, where it is an integral part of the primary school mathematics curriculum. The first element of geometry is introduced in Primary 5 under the heading "plane shapes". The objectives at this early stage is to teach pupils how to;

i. Identify various plane figures.

ii. $\quad$ Calculate the perimeter and area of plane figures.

In Primary 6, the pupils do further work on the objectives at this level to teach the pupils how to calculate the area of some compound two-dimensional shapes.

At the secondary school, the elements of geometry are integrated into the mathematics and further mathematics curriculum. The geometric concepts taught at the primary school are usually revised at the Junior Secondary School level. The following topics are studied under geometry content as contained in the Senior Secondary School Mathematics Curriculum (2007);
a. Plane Geometry
b. Geometric construction 


\section{c. Mensuration}

d. Trigonometry

\section{e. Coordinate Geometry}

By learning geometry students may be able to identify shapes and space around them. Geometry can also help them represent their surroundings. The comprehension of geometry models and their properties may give students a new perspective in their ability to analyze and communicate geometry-related things in their daily lives. The National Council of Teachers of Mathematics (NCTM, 2004), have emphasized the importance of geometry in school mathematics by stating that; geometry and spatial sense are fundamental components of mathematics learning. They offer ways to interpret and reflect on our physical environment. Geometry allows students to develop insight to understand other mathematical concepts and connect ideas across different areas of mathematics (Sunzuma, 2017). Furthermore, many ideas like symmetry or generalizations can help students increase insights into the nature and beauty of mathematics (NCTM, 2004). The importance of geometry is best stated by an inscription above the door of Plato's school; “Let no one destitute of geometry enter my doors” (Sunzuma, 2017).

Regardless of the importance of geometry in real life situations and the subsequent action of making it a content in mathematics curriculum, students have continued to dislike it and hence, poor performance has always been the outcome. Analysis of school certificate mathematics examinations results in Bayelsa State, reveals that students' have consistently low scores, as less than $42 \%$ of registered candidates obtain credit pass (Appendix XV). West African Senior School Certificate Examination Council, Chief Examiner's Report on students' areas of deficiency in school certificate examinations for eight (8) years (2010-2018), revealed that geometry content has consistently been termed as an area of weakness in terms of their achievement (Appendix XIV). Abakpa and Iji (2011) reported that students often avoid geometry questions or haphazardly attempt them. Mammana and Villiani (2018) also discovered that students' geometry achievement was always lower than the other areas of mathematics. They further noted that students shy away from the study of geometry. Zeycep (2010) reported that students have difficulties in learning geometry and in thinking geometrically. He further asserted that many geometrical problems require certain visualization in problem solving and students generally find it difficult to construct three-dimensional spaces.

Research reports have revealed that many reasons account for students' poor achievement in geometry. Among these are poor teaching approach (Olunoye, 2010), lack of interest and confidence in the subject (Arbain, 2015), poor learning environment (Olunoye, 2010).Similarly, Somalia (2019), Bilesanmi and Afuwape (2017), Ado (2018) reported that gender differences and students' choice of discipline are latent factors that affects students achievement in geometry. 
Gender, according to Offor (2010), refers the social relations between men and women, that although it could be directed by sex, which refers to the biological differences between them, it has nothing to do with physiological characters. To Ewhrudjakpor (2016), gender refers to culturally patterned behaviors either actual or normative which are attached to sexes. It involves masculinity or femininity. Vale (2009), Abiam and Odok (2016) reported that gender differences in mathematics achievement exist but that it reduces with time. Analyzing the WAEC result of 2018, Uwaidiace (2018) reported that $7.32 \%$ and $6.42 \%$ of male and female students respectively obtained credit pass. Specifically, Abiam and Odok (2016) found that there is no significant relationship between gender and achievement in number and numeration, statistics, algebra but a week relationship between gender and achievement in geometry. Also, Amelink (2019) indicated that male students performed better in geometry and menstruation, while female students performed better in number and numeration content. Benbow (2013) reported a significant difference in geometry ability between male and female students, whereas Gamage and CharlesOgan (2019) stated that the difference was not significant. Armstrong (2018), Fennema (2018) reported that girls fall behind in geometry learning in the primary school and further on in junior secondary school. They further reported that gender have no significant difference on geometry achievement in senior secondary school. Thus, there is need for more studies on the instructional strategies that can enhance equal achievement among male and female students in geometry which necessitates this study.

In Nigeria, there are two categories of public secondary schools, when schools are been classified based on ownership; those owned by the Federal Government and those owned by the state government (Akpe, 2016). The secondary schools owned by the Federal Government are also called Federal Unity Schools and there are one hundred and four (104) across the nation. Learners' choice of discipline has to do with science/engineering and arts/commercial classes that students belong to depending on their future career (Bilesanmi \& Afuwape, 2017). Science students refers to students offering science subjects such as Physics, Chemistry, Biology as their core subject, while arts students are those offering Literature-in-English, Government, Economics, Commerce, Christian Religious Study (CRS) as their core subjects. In Federal Government Colleges, students are usually divided into four streams, two sciences and two arts classes The choice of discipline on students' achievement in mathematics is a major issue that has not produced conclusive results. So, many studies on science and arts students' performance in mathematics exist, but there is scarce research evidence on issues relating to differences in the achievement of Arts and Science student in geometry content only. Somalia (2019) researched on the influence of choice of discipline on the performance of secondary school students in mathematics and reported that science students performed better than their arts counterparts. Bilesanmi and Afuwape (2017) reported that when the right teaching strategy is adopted, learning outcome of both science and arts students will improve. It is worthwhile to check how the achievement and interest of science and arts students will be in geometry, when mobile app instructional technique is utilized. 
Different teaching and learning methods have been experimented to motivate and increase learners' achievement and interest in geometry. Examples of such learning method are, Mastery Learning Approach (Abakpa \& Iji, 2011), the Use of Geogebra (Arbain, 2015), the Use of Geometry Learning Media based on Augmented Reality (Rohendi, 2018), Geometers Sketchpad (Dimakos, 2010), Digital Geometric Software (Hasan, 2012), Cabri Geometry Plus II (Derya, 2012), Digital Daily Life Photograph (Zeycep, 2010), Daily-Life Story Using Dynamic Geometry Software (Abdelfatah, 2010), Personal Math Concept Chart (Rhonda, 2017).

Teachers have the potential of exerting strong influence on students' learning. Uloko and Usman (2018) reported that there is a positive correlation between good teaching approach and students' learning in geometry. Also, Abkpa and Iji (2011) stated that good strategy improves both low and high ability students in geometry at upper basic education class. That is good teaching approach produces high achievement among learners, while poor teaching approach will lead to poor learning and low achievement. Rossing (2012) submitted that changes in technology will continue to alter possibilities for learning and create new challenges for pedagogy. Also Etcuban (2018) opined that increased development in technology coupled with a range of needs and expectations from a range of stakeholders have made it imperative for educational organizations to constantly upgrade their strategies and policies in teaching and learning as a way to remain effective and competitive. Etcuban (2018) noted that students all over the world are very much comfortable with electronic gadgets and equipment and the need to use these gadgets and equipment in teaching is highly evident. Also mobile computing is explored primarily because many of the learners spend more time with their mobile devices than any other toy or learning materials. Some of the learners have even become addictive to the use of their Mobile devices for other activities such as games.

Mobile application instructional techniques also known as mobile application instructional techniques are a series of application designed to assist learners in performing single or various related tasks with the purpose of creating learning. The use of mobile application instructional techniques represents a technology that is ubiquitous in nature, wireless, highly portable and endowed with multimedia capabilities bringing a new dimension to curriculum delivery (Fuchs, 2014). The last ten years have witnessed an impressive increase in the use of mobile application instructional technique in schools (Ectuban, 2018). Although, created for non-educational environment, tools like tablets and smartphones have made their way into the classroom. These devices with learning applications have attracted interest from the educational communities mainly due to their gaming capabilities. The use of mobile application instructional technique allows students to engage in problem-solving based learning activities, permits students to work on tasks that are goal oriented and open-ended with a strong gaming component. They empower students to develop their own understanding through active involvement and sense-making. Furthermore, learning experiences like digital simulations or manipulations have the capacity to bring interactivity, thus enhancing cognitive and affective processes (Barros \& Marcos, 2010). 
Etcuban (2018) observed that the use of mobile devices such as cell phones and tablets are among the six new rising advances that have significantly affected instruction delivery. Particularly, in the subject matter of mathematics, Ruthven and Hennessy (2012) made a comparison between the learning outcomes of mobile-based teaching and mathematics thematic teaching; results revealed that mobile-based learning significantly improved the advancement of scientific aptitude and the development of a more profound perceptual ability for the students. The Nigerian government recognizes the importance of ICT as a tool for development of the country. It has stressed that ICT has a role to play in education both directly as a subject and indirectly as a tool to assist in instruction delivery and management (NMC, 2015). As a way to match actions with words, the School Based Knowledge Centre Project, launched in 2014 by the Federal Government, through the Nigerian Communication Commission (NCC), supplied smartphones to all Federal Unity schools and some state owned secondary schools (NMC, 2015). This marked the advent of the use of mobile devices as an instructional aide in teaching and learning in Government owned secondary schools across the country.

Mobile app designed specifically for geometry used in this study is Apollonius which is an interactive, measurement, and simulation app. It allows you to create geometric constructions, such as those that can be made using a ruler and a compass and subsequently move parts of your constructions to explore the relationship between the geometric objects on the screen. Its interface is especially designed for touch screen, providing one of the smoothest experiences of any existing interactive geometry app (Handal and Herrington, 2013). It is inspired by software such as Geogebra, the Geometer's Sketchpad and Cabri. The choice of Apollonius was predicated on the fact that it can be installed on every kind of smartphone (IOS devices) and can be used in the teaching and learning of mathematics without internet connections and it is designed specifically for geometry.

\section{Statement of Problem}

The achievement of students in mathematics has been quite unsatisfactory over the years in Nigeria particularly in Bayelsa State (see appendix XIV). The external examination bodies such as the West African Examination Council (WAEC) and the National Examination Council (NECO) have repeatedly reported the poor performance of students in mathematics. The picture emerging from research reports, Chief Examiners' reports and WAEC and NECO SSCE results (2010-2018) as in appendix XIV, show that the students have major and consistent difficulty in solving mathematical problems that involves geometry. Students' low success levels in mathematics have been a source of worry for a long time in many countries, Nigeria inclusive. There are a lot of factors said to be affecting students' achievement in geometry, one of these according to Adolphus (2011), Gamage and Charles-Ogan (2019), Agwagah, (2019) is the conventional pattern of teaching mathematics which has been identified as being ineffective. In addition, other reasons pointed out by different scholars, Ado (2018), Ajaegba and Ekwueme (2019), Mman and Tukunkaya (2019) are poor learning interest and assimilation of mathematics ideas, concepts, principles, processes and teachers' failure to use appropriate and stimulating 
teaching methods are responsible for students' low achievement in geometry in Nigeria. Similarly, Somalia (2019), Bilesanmi and Afuwape (2017), Ado (2018) reported that gender issues and students' choice of discipline as it affects achievement in geometry are yet inconclusive thus; needs more verification.

Though, much attention has been directed towards the study of mathematics at the primary and secondary levels of education as to improve students' achievement, regrettably, this has not given the required result of improved achievement in our schools. In a bid to overcome the problem associated with the learning of geometry, mathematics educators have resorted to the use of developed mobile application instructional techniques as an instructional aide. Etcuban (2018), Burden, (2010), Khristin, Keith and Barron (2018) reported that the use of mobile application based pedagogy in the teaching and learning of geometry and other aspects of mathematics in other countries have yielded improved results. There is a dearth of empirical evidence on the teaching of geometry using mobile application instructional technique to enhance students' achievement and interest in geometry in Nigeria. Therefore, the problem of the study put in question form is; would the use of mobile application instructional technique be an effective way of improving students' achievement and interest in geometry in Bayelsa State?

\section{Purpose of the Study}

The purpose of this study is to determine the effects of teaching geometry using mobile application instructional techniques on secondary school students' achievement in Bayelsa state. Specifically, the study sought to;

i. Determine the mean achievement scores of students taught geometry using mobile application instructional techniques and those taught using lecture method.

ii. Determine the mean achievement scores of male and female students taught geometry using mobile application instructional techniques.

iii. Determine the mean achievement scores of science and arts students taught geometry using mobile application instructional techniques.

\section{Research Questions}

The following research questions were formulated to guide the study;

1. What are the mean achievement scores of students' taught geometry using mobile application instructional techniques and those taught using lecture method?

2. What are mean achievement scores of male and female students taught geometry using mobile application instructional techniques?

3. What are the mean achievement scores of science and arts students taught geometry using mobile application instructional techniques? 


\section{Research Hypotheses}

The following null hypotheses were formulated and tested at 0.05 level of significance

Ho1: There is no significant difference between the mean achievement scores of students taught geometry using mobile application instructional technique and those taught using lecture method.

Ho2: There is no significant difference between the mean achievement scores of male and female students taught geometry using mobile application instructional techniques.

Ho3: There is no significant difference between the mean achievement scores of science and arts students taught geometry using mobile application instructional techniques.

\section{RESEARCH METHODOLOGY}

A pre-test, post-test, non-equivalent control group quasi-experimental design was adopted for the study. The choice of this design allowed investigation of intact groups in real-life classroom setting, since it was not possible to randomly assemble students for any intervention during school hours so as to avoid artificial conditions. The population for this study was all the 506 mathematics students in the 3 federal government unity colleges in Bayelsa State. A sample of one hundred and seventy nine (179), second year senior secondary school (SS2) students was used for the study. Since all the Federal Government Colleges are the only schools with the Knowledge Based Centers, where the mobile devices are available, the two co-educational Federal Government Colleges were purposively selected. Also, SS2 class was purposively selected because there was no impending external examination that could distract students from full participation in the study and the content used was meant for them as contained in the senior secondary mathematics curriculum. In each school, there are 2 classes for science and 2 classes for arts making a total of 8 classes in both schools selected for the study. Simple random sampling by flipping of the coin was used to select one out of the two science classes and one out of the two arts classes from each school, thereby making it a total of four classes to participate in the study. Allocation of the classes into experimental and control group was done by random sampling through balloting, which resulted to two (2) classes assigned to experimental group and the other two(2) to the control group. All the one hundred and seventy nine (179) SS2 students in the four streams of the selected schools formed the sample of the study. The instrument for data collection was Geometry Achievement Test (GAT) developed by the researchers. GAT comprises of two parts, namely part 1 and II. Part I solicited the personal data of the participants, while part II had 40-items consisting of ten (10) items on chord property, 6-items on arc theorem, 6-items on semi-circle theorem, 6-items on segment theorem, 6-items on cyclic quadrilateral theorem and 6-items on alternate segment theorem, based on the SS2 scheme of work contained in the mathematics curriculum for senior secondary school produced by NERDC (2015). The WAEC past questions selected from 2010-2019 examination items were used to formulate the 
GAT. The 40 items were multiple choice objectives questions with four options (A, B, C and D). Each question correctly answered gave 1mark, which gives a total of 40marks for the 40 question. The instrument was validated by experts in mathematics education unit of science education department and Measurement and Evaluation of Rivers State University, Port Harcourt. A trial testing was carried out in the other school that was not involved in the study, but possesses the same characteristics as the one involved in the study. Thirty (30) students involved in the trial testing were given the GAT and GII. The data obtained were used to determine the internal consistency of the item. This was done through the use of KuderRichardson Formula $(\mathrm{KR}-20)$. This is because the GAT items are dichotomously scored (either pass or fail). This reliability index was found to be 0.79 . Before the commencement of the experiment, the researcher administered the pre-GAT and pre-GII to all the students in both groups. The scores were collated for use after the experiment. The post-GAT and post-GII was administered to all the students in both groups after the lessons. Statistical Package for Social Science (SPSS) software version 21 was used to analyze the data. The research questions were answered using mean $(\bar{x})$ and standard deviation (SD). The research hypotheses were tested at 0.05 levels of significance using Analysis of Covariance (ANCOVA). ANCOVA is an extension of Analysis of Variance that allows for the exploration of the differences between groups, while statistically controlling for an additional variable called the Covariate (Pallant, 2018). The preGAT and pre-GII scores served as the covariates.

\section{RESULTS AND DISCUSSION OF FINDINGS}

\section{Research Questions}

\section{Research Question 1}

What are the mean achievement scores of students' taught geometry using mobile application instructional techniques and those taught using lecture method?

Table 1: Mean Achievement Scores and Standard Deviation of Students Taught Geometry Using Mobile app-based instructional techniques and Lecture Method

\begin{tabular}{lcccccc}
\hline \multirow{2}{*}{ Groups } & \multicolumn{3}{c}{ Pre-Gat } & \multicolumn{2}{c}{ Post-Gat } & \multicolumn{2}{c}{ Mean Gain } \\
& & $\overline{\boldsymbol{x}}$ & SD & $\overline{\boldsymbol{x}}$ & SD & 20.72 \\
\hline Experimental & 86 & 5.91 & 2.90 & 26.63 & 6.57 & 10.33 \\
Control & 93 & 7.52 & 3.63 & 17.90 & 3.96 & \\
\hline
\end{tabular}

Table 1 shows that the experimental group which was those taught using mobile app instructional techniques obtained a mean achievement score of 5.91 and standard deviation of 2.90 in the Pre-GAT and a mean achievement score of 26.63 and standard deviation of 6.57 in the Post-GAT. It was also revealed that the control group which represents those taught using lecture method obtained a mean achievement score of 7.52 and standard deviation of 3.63 in the Pre-GAT and a mean achievement score of 17.90 and standard deviation of 3.96 in the PostGAT. The standard deviations of students taught geometry using MAIT and lecture methods increased from pre-GAT to post-GAT indicating that the scattering of the scores increases as the 
mean increased. The scattering of the scores was higher for those taught geometry using MAIT when compared to those taught geometry using lecture method. The mean gain between PreGAT and Post-GAT for experimental and control groups are 20.72 and 10.33 respectively. This implies that students taught geometry using mobile application instructional techniques had a higher mean gain than those taught using the lecture method.

Research Question 2: What are mean achievement scores of male and female students taught geometry using mobile app instructional techniques?

Table 2: Mean Achievement Scores and Standard Deviation of Male and Female Students Taught Geometry Using Mobile app instructional techniques

\begin{tabular}{lcrrrrl}
\hline \multirow{2}{*}{ Sex } & $\mathbf{N}$ & \multicolumn{2}{c}{ Pre Gat } & \multicolumn{2}{c}{ Post-Gat } & \multirow{2}{*}{ Mean Gain } \\
& & $\overline{\boldsymbol{x}}$ & SD & $\overline{\boldsymbol{x}}$ & SD & \\
\hline Male & 43 & 7.01 & 3.43 & 22.71 & 6.86 & 15.70 \\
Female & 43 & 6.48 & 3.34 & 21.44 & 6.97 & 14.96 \\
\hline
\end{tabular}

The table above shows that the male students in the experimental group had a mean achievement score of 7.01 and standard deviation of 3.43 in the Pre-GAT and a mean achievement score of 22.71 and standard deviation of 6.86 in the Post-GAT. It was also revealed that the female students in the experimental group obtained a mean achievement score of 6.48 and standard deviation of 3.34 in the Pre-GAT and a mean achievement score of 21.44 and standard deviation of 6.97 in the Post-GAT. The standard deviations of male and female students taught geometry using MAIT increased from pre-GAT to post-GAT indicating that the scattering of the scores increased as the mean increased. The scattering of the scores was higher for female students compared to their male counterparts taught geometry using MAIT. The mean gain between PreGAT and Post-GAT of male and female students taught geometry using mobile applicationbased instructional techniques is 15.70 and 14.96 respectively. 
Research Question 3: What are the mean achievement scores of science and arts students taught geometry using mobile app instructional techniques?

Table 3: Mean Achievement Scores and Standard Deviation of Arts and Science Students Taught Using Mobile Application

\begin{tabular}{lcccccc}
\hline \multirow{2}{*}{ Choice of discipline } & \multirow{2}{*}{ Pre Gat } & \multicolumn{2}{c}{ Post-Gat } & \multirow{2}{*}{ Mean Gain } \\
& & $\overline{\boldsymbol{x}}$ & SD & $\overline{\boldsymbol{x}}$ & SD & \\
\hline Science students & 52 & 6.01 & 2.99 & 23.10 & 7.11 & 17.09 \\
Arts students & 34 & 6.48 & 3.60 & 21.13 & 6.63 & 14.65 \\
\hline
\end{tabular}

The table 3 shows that the science students in the experimental group had a mean achievement score of 6.01 and standard deviation of 2.99 in the Pre-GAT and a mean achievement score of 23.10 and standard deviation of 7.11 in the Post-GAT. It was also revealed that the arts students in the experimental group obtained a mean achievement score of 7.47 and standard deviation of 3.60 in the Pre-GAT and a mean achievement score of 21.13 and standard deviation of 6.63 in the Post-GAT. The standard deviations of science and arts students taught geometry using MAIT increased from pre-GAT to post-GAT indicating that the scattering of the scores increased as the mean increased. The scattering of the scores was higher for science students compared to their arts counterparts taught geometry using MAIT. The mean gain between Pre-GAT and Post-GAT of science and arts students taught geometry using mobile app-based instructional techniques is 17.09 and 14.65 respectively. This implies that science students taught geometry had a higher mean gain than their arts counterparts.

\section{Testing Hypotheses}

Hol: There is no significant difference between the mean achievement scores of students taught geometry using mobile app instructional technique and those taught using lecture method.

Table 4: Summary of Analysis of Covariance on Experimental and Control Group

\begin{tabular}{lllllll}
\hline Source & $\begin{array}{l}\text { Type III Sum Df } \\
\text { of Squares }\end{array}$ & Mean Square & F & Sig. & $\begin{array}{l}\text { Partial Eta } \\
\text { Squared }\end{array}$ \\
\hline Corrected Model & $3500.785^{\mathrm{a}}$ & 2 & 1750.392 & 61.229 & .000 & .410 \\
Intercept & 14945.017 & 1 & 14945.017 & 522.781 & .000 & .748 \\
PREGAT & 90.550 & 1 & 90.550 & 3.167 & .077 & .018 \\
METHOD & 3479.330 & 1 & 3479.330 & 121.708 & .000 & .409 \\
Error & 5031.405 & 176 & 28.588 & & & \\
Total & 95962.000 & 179 & & & & \\
Corrected Total & 8532.190 & 178 & & & & \\
\hline
\end{tabular}

Summary of data analysis presented in table 4 shows that the main effect, teaching method has fcalculated value of 121.708 and a p-value of 0.00 which is less than the critical p-value of 0.05 . This is based on 1 degree of freedom for numerator and 178-degree of freedom for denominator. Thus, the null hypothesis is rejected. This implies that there is a significant difference between the mean achievement scores of students taught geometry using mobile app instructional technique and those taught using lecture method. 
$\mathrm{Ho}_{2}$ : There is no significant difference between the mean achievement scores of male and female students taught geometry using mobile app instructional technique

Table 5: Summary of Analysis of Covariance of Experimental Groups on Achievement due to Gender

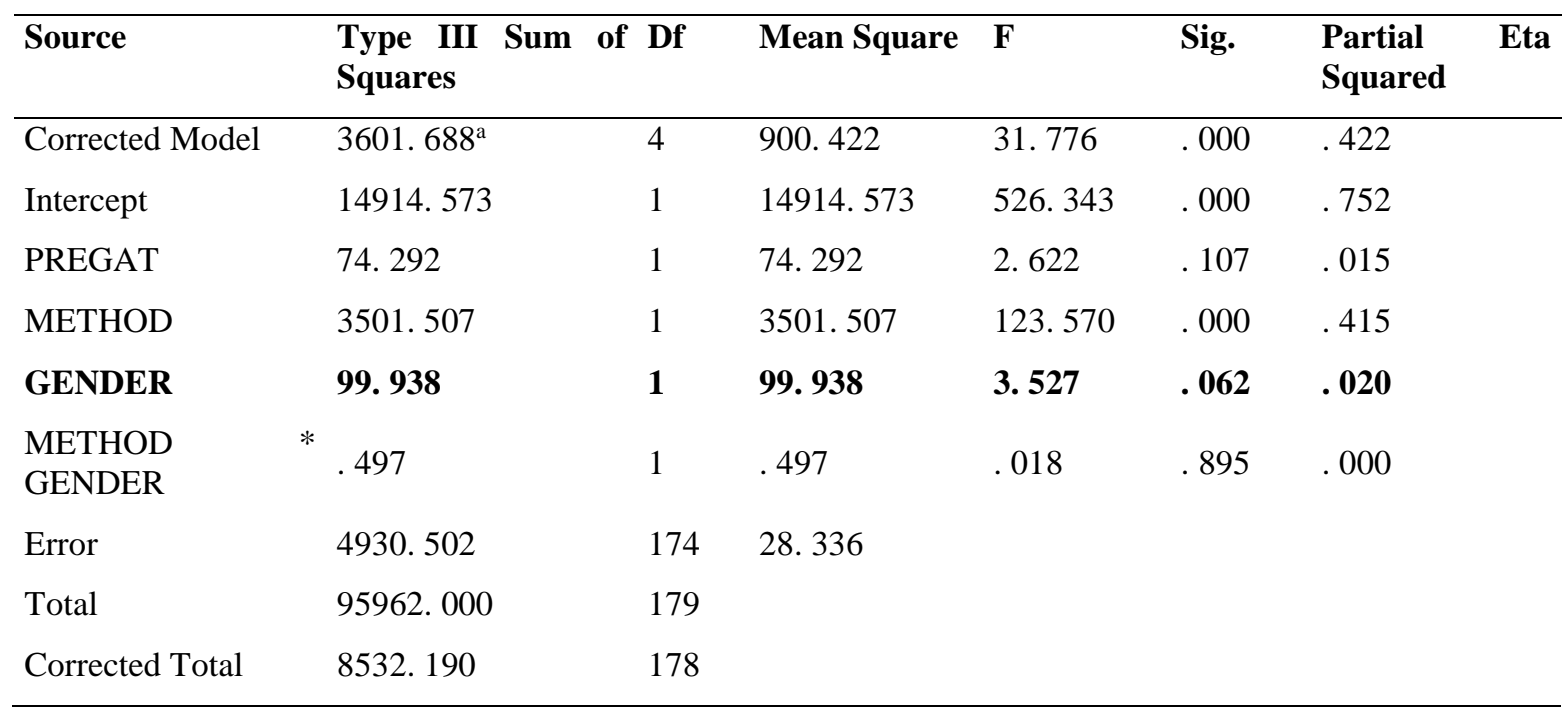

The results presented in table 5 above shows that the main effect, gender, has f-calculated value of 3.527 and a p-value of 0.062 which is greater than the critical p-value of 0.05 . This means that the null hypothesis is not rejected. That is, the difference between the mean achievement scores of male and female students taught geometry using mobile app instructional technique is not statistically significant.

Ноз: There is no significant difference between the mean achievement scores of science and arts students taught geometry using mobile app instructional techniques.

Table 6: Summary of Analysis of Covariance of Experimental Groups on Achievement due to Choice of Discipline

\begin{tabular}{llllllll}
\hline Source & $\begin{array}{l}\text { Type III Sum of Df } \\
\text { Squares }\end{array}$ & Mean Square & F & Sig. & Partial Eta Squared \\
\hline Corrected Model & $3607.314^{\mathrm{a}}$ & 4 & 901.828 & 31.862 & .000 & .423 \\
Intercept & 14189.954 & 1 & 14189.954 & 501.343 & .000 & .742 \\
PREGAT & 93.343 & 1 & 93.343 & 3.298 & .071 & .019 \\
METHOD & 3327.112 & 1 & 3327.112 & 117.550 & .000 & .403 \\
CHOICE & $\mathbf{6 . 3 0 9}$ & $\mathbf{1}$ & $\mathbf{6 . 3 0 9}$ & $\mathbf{. 2 2 3}$ & $\mathbf{. 6 3 7}$ & $\mathbf{. 0 0 1}$ \\
METHOD & $*$ & 101.790 & 1 & 101.790 & 3.596 & .060 & .020 \\
CHOICE & 4924.876 & 174 & 28.304 & & & \\
Error & 95962.000 & 179 & & & & & \\
Total & 8532.190 & 178 & & & & \\
Corrected Total & & & & & & &
\end{tabular}

The result presented in table 6 above shows that the main effect, choice of discipline, has $\mathrm{f}$ calculated value of .223 and a p-value of .637 which is greater than the critical p-value of 0.05 . This means that the null hypothesis is not rejected. Therefore, the difference between the mean 
achievement scores of science and arts students taught geometry using mobile app instructional techniques is not, statistically significant.

\section{Summary of Findings}

The summary of the findings of this study are as follows:

1. There is a significant difference between the mean achievement scores of students taught geometry using mobile app instructional technique and those taught using lecture method.

2. There is no significant difference between the mean achievement scores of male and female students taught geometry using mobile app instructional technique

3. There is no significant difference between the mean achievement scores of science and arts students taught geometry using mobile app instructional techniques

\section{Discussion of Findings}

The discussion of findings is done based on research questions and hypotheses.

\section{Method and students achievement in geometry}

The findings on method and students achievement in geometry revealed that the mean achievement scores of students in the experimental group were higher than those in the control group. The finding also revealed that, students taught using mobile app instructional technique performed significantly better than those taught using lecture method. This in general revealed that Mobile Application Instructional Technique which provides the enabling environment to motivate students to discuss as well as allow them to develop spatial thinking and easy visualization of geometric concept can produce differential effects on students with respect to their achievement. This finding aligns with Bhagat and Chang (2015), Weng-Hung (2018), Abeh (2018), Tetzlaff (2017) who reported a significant difference in favour of the use of the mobile app on students' achievement. On the contrary the unhealthy achievement by the control group may be attributed to lack of inadequate materials and students not having the technical skills of constructing the geometric shapes as well as not knowing the rigorous ways of getting proofs done. This supports Kultuca (2013), Ectuba (2018), Yeng and Chieng (2017), Ehrk(2017) and Supandi (2018) who reported that the use of mobile apps appeals to more learning modalities, when compared to lecture method which appeals to only auditory learning modalities.

\section{Method, Gender and Students Achievement in Geometry}

The findings gender achievement taught using mobile app instructional technique revealed that the mean gain of male students in the experimental group was higher than that of their female counterparts. The finding also indicated that gender was not statistically significant in terms of their achievement in geometry. This finding could be attributed to the use of mobile app instructional technique (MAIT) which creates a platform where students irrespective of gender 
can exchange ideas, participate and corroborate competitively during classroom activities, which may have resulted to the enhancement of equal achievement of male and female students. This indicated that the use of mobile app instructional technique bridged gender gap in mathematics achievement. This finding is in line with Hilalo, (2017) Chung \&Rong-chil (2017), Pitchford (2018) who reported a non-significant difference in the achievement of male and female students in geometry when digital game-based learning approach was used. It also supports the finding of Gamage and Charles-Ogan (2018), who reported that achievement is a function of motivation, effort, ability, confidence and orientation emanating from the teaching strategy adopted not gender. On the contrary the finding disagrees with Abdulkarime (2019) who reported significant difference in the mean achievement scores in favour of males, when compared to their female counterparts.

\section{Method, Choice of Discipline and Students Achievement in Geometry}

The findings on the mean achievement scores of science and arts students taught geometry using mobile app instructional technique revealed that the mean gain of science students in the experimental group was higher than that of their arts counterparts. The finding also indicated that choice of discipline was not significant in terms students achievement in geometry. This could be attributed to the use of mobile app instructional technique (MAIT) which creates an avenue for students irrespective of their choice of discipline to learn geometry by practice during classroom activities. This indicated that the use of mobile app instructional technique bridged the gap existing between science and arts students in geometry achievement. This finding aligns with AlTakhyneh (2018) who reported that the use of mobile applications enables the students in arts, science and commercial to interact directly with the educational content. This finding also supports Akintade (2017) who reported that the use of ICT tools devices enabled students to represent construction graphically, carry out suitable and over lapping geometric transformations, and control the properties of the angles and lines on the contrary. However, this finding was contrary to the early findings of Somaila (2019), Abiam and Odok (2016), Ado (2019) who reported a significant difference in the mean achievement in mathematics in favour of science students, when compared with their arts counterparts in mathematics.

\section{Conclusion}

The study established that mobile application instructional technique was more effective than lecture method; for students taught geometry using MAIT had a higher achievement scores than those taught using lecture method. Mobile application instructional technique also bridged the gap between male and female as well as science and arts students' achievement and in geometry. 


\section{Recommendations}

Considering the above findings, of the following recommendations were made;

1. Teachers should be encouraged to implement mobile application instructional technique in the teaching and learning of geometry and mathematics in Nigerian secondary schools in order to enhance students' achievement.

2. Government and other stakeholders should ensure that teachers are trained adequately to enable them utilize mobile devices for teaching and learning purpose.

3. Students must have regular access to the use of mobile devices that support learning so as to advance their achievement and interest in mathematics, especially geometry.

4. Curriculum planners and indigenous authors should include the features of mobile app instructional techniques in the curriculum and mathematics textbooks so that teachers and students will be inspired to harness the potential benefits associated with its use for improved achievement and interest in mathematics.

\section{REFERENCE}

1. Abdelfatah, H. (2010). Improving Undergraduates Students' Attitude towards Geometric Proof through a Daily-Life Story Using Dynamic Geometry Software. Journal of Turkish Mathematics, 12(3), 1 19.

2. Abakpa, B.O. \&Iji, C.O. (2011). Effect of Mastery Learning on Senior Secondary School Students' Achievement in Geometry. Journal of Science Teachers Association of Nigeria, 1, 165-176.

3. Abdulkarim, A., Bomala, I. \& Abimbola, N.G.A. (2019). Effect of ICT-Driven Pedagogy on the Academic Achievement of Secondary School Students within Gombe Metropolis in Geometry. ABACUS, 44(1), 144-150.

4. Abeh, A. Abah, B. \& Abakpa, B.O. (2018). Perceptions of Undergraduate Mathematics Students on the Use of Tech Augmented Learning Approach in Teaching Matrices Algebra in North Central Zone of Nigeria. International Referred Journal of Arts, Science and Commerce, 6(1), 121-131.

5. Abiam, P.O. \& Odok, J.K. (2016). Factors in Students' Achievement in Different Branches of Secondary School Mathematics. Journal of Education and Technology, (1), 161-168.

6. Adenegan K.E. (2012). Setting Mathematics Laboratory in Schools, Journal of Education and Technology 12(2), 5-6.

7. Ado. I. B. (2018). Mathematics club: A panacea of students' interest and performance in mathematics in Yenagoa Education zone of Bayelsa State, Nigeria Journal of Education and social policy, 5 (3), $182-188$.

8. Adolphus, T. (2011). Problems of the teaching and learning of geometry in secondary schools in Rivers state, Nigeria. International journal of emergence science, 1(2), 143-152

9. Ajaegba, N.M. \& Ekwueme, C.C. (2019). Application of GeoGebra Software and Students' Performance in Plane Geometry in Secondary Schools in Delta State. ABACUS, 44(1), 10-19. 
10. Akintade, C.A. (2017). Effect of Computer Assisted Instruction on Students' Achievement and Attitude towards Latitude and Longitude in Ogun State, Nigeria. Unpublished Ph. D. Dissertation in Mathematics Education, University of South Africa.

11. Akpe, P.P. (2016). Comparative Evaluation of Material Resources for Teaching in Public and Private Basic Schools in Bayelsa State. Niger Delta Journal of Education, 8(2) 131-145.

12, Amelink, C.T. (2019). Literature Overview: Gender Difference in Mathematics Performance. Retrieved from http://www.AWEonline.org on 20/05/2011.

13. Arbain, N. (2015). Effects of Geogebra on Students Achievement Procedia Social and Behaviour Sciences. 172 (2015), 208-214.

14. Armstrong, D.A. (2018). Students' Perceptions of Online Learning and Instructional Tools: A Qualitative Study of Undergraduate Students Use of Online Tools. Turkish Online Journal of Educational Technology - (TOJET), 10(3), 222-226.

15. Barros, S., \&Marcos F.E. (2010). How do they affect the reality of the classroom and models for change? http://www.physics.ohi-state.edu/jossen/ICPE/02.html

16. Bhagat, K.K. \& Chang, C.Y. (2015). Incorporating Geogebra into Geometry Learning. Eurasia Journal of Mathematics, Science and Technology Education, 11(1), 77-86.

17. Bilesanmi, G. \& Afuwape, H. (2017). Influence of study interest and school location on the attitude of secondary school student towards mathematics in Ekiti State Nigeria: Greener Journal of Educational Research, 3(6), $229-232$.

18. Charles-Owaba, T. (2018). Effects of Traditional Games on Students' Achievement in Mathematics. Journal of Contemporary Research, 9(3), 150-164.

19. Chung, T. \& Rong-Chil, R. (2017). Impact of Learners' Gender on Learning Outcomes and Motivation in Mathematics using Digital Game-Based Learning Approach. Journal of Educational Technology, 17(4), 17-32.

20. Derya, O. (2012). Teaching Transformation Geometry with Cabri Geometry Plus II. Procedia, Social and Behavioural Science 46 (2012), 5187-5191.

21. Dimakos, G. (2010). The Influence of the Geometers' Sketchpad on the Geometry Achievement of Greek School Students. Journal of Teaching of Mathematics, 12(2), 113-124.

22. Ectuban, J.O. (2018). The Effects of Mobile Application in Teaching High School Mathematics. International Electronic Journal of Mathematics Education, 13(3), 249-259.

23. Ehrke, U. (2017). Assessing the Efficacy of Mobile Computing Platforms in Mathematics via Mobile Learning Usability Scale. Journal of Teaching and Learning with Technology, 1(2), 13-25.

24. Fennema, E. (2018). Teachers' Beliefs and Gender Differences in Mathematics. Fennema and Leder (Eds). Mathematics and Gender, Columbia University, New York (169-187).

25. Fuchs, K. (2014). Dynamic Mathematics with Geogebra. The Journal of Online Research in Mathematics, 7(3), 123-129

26. Gamage, T. \& Charles-Ogan, G. (2019). GeoGebra Software and Students' Performance in Teaching and Learning of Circle Geometry. ABACUS, 44(1), 480-489. 
27. Handal, B. \& Herrington (2013). Re-Examining Categories of Computer-Based Learning in Mathematics Education. Contemporary Issues in Technology and Teacher Education, 2(1). Retrieved August 5, 2013, from http://www.citejournal.org/vol3/iss3/mathematics/article1.cfm

28. Hasan, F. (2012). The Effect of Dynamic Mathematical Software Geogebra on Achievement in Teaching of Trigonometry. Procedia, Social and Behavioural Sciences, 31(2012), 183-187.

29. Hilao, M.P. \& Wichadee, S. (2017). A Comparative Study on Female and Male Students Perception on the Use of Mobile Phones as a Learning Tool for Mathematics. Turkish Online Journal of Distance Education 18(2), 68-78.

30. Keith, J. (2017). Mobility at Work; A Topology of Mobile Communities of Practice and Contexture Ambidexterity. In Journal of Strategic Information Systems, 13(4), 223-236

31. Khristin, C. Keith K. \& Barron, J. (2015). Interest towards Teaching Mathematics via Mobile Learning in Open Learning Systems in Arab Open University. International Conference on Mathematics, Science and Education doi:10.1088/1742-6596/983/1/01206.

32. Mammana, C. \&Villiani, V. (2018). Geometry and Geometry-Teaching through Ages. Journal of Computers in Mathematics and Science Teaching, 27(4), 321-340

33. Mman, S.S. \& Tudunkaya, M.S. (2019). Effects of Web-Based Practice on Academic Performance in Coordinate Geometry among Colleges of Education Students in North-West Zone Nigeria. ABACUS, 44(1), 90-98.

34. National Council of Teachers of Mathematics NCTM, (2010). Principles and Standard for school Mathematics, Reston, VA

35. Olunloye, O. (2010). Mass Failure in Mathematics: A National Disaster. Tribune of 07/02/2010 retrieved from http://www.tribune.com.nig on 08/05/2011.

36. Pallant, J. (2018). SPSS Survival Manual: A Step-by-Step Guide to Data Analysis using SPSS for Windows (Version 10 \& 11). Australia: Glasgow, Bell and Bam Ltd.

37. Pitchford, N.J., Chigeda, A. \& Hubber, P.J. (2018). Effects of Technology-based Intervention on Students' Achievement in Mathematics based on Gender. Front Psycho, 6(3), 485-495.

38. Rhonda, F. (2017). Increasing Communication in Geometry by Using Personal Math Concept Chart. Canadian Journal of Action Research. 12(2), 30-39.

39. Rohendi, D. (2018). The Use of Geometry Learning Media Based on Augmented Reality for Junior High School Students. 201810Pconf. series. MatterSci. Eng. 306, 1-10.

40. Roosing, J.P. (2012). iLearning: The Future of Higher Education? Students Perceptions of Learning with Mobile Tablets. Journal of Scholarship of Teaching and Learning, 12(2), 1-26.

41. Ruthven, K. \&Hennessy, S. (2012). A Practitioner Model of the Use of Computer-Based Tools and Resources to Support Mathematics Teaching and Learning,Educational Studies in Mathematics, 49(1), 47-88.

42. Somalia, M.U. (2019). Comparative Analysis of Students Performances in Basic General Mathematics among some Selected Arts and Science Students of CAS Kano. ABACUS, 44(1), 99107. 
43. Sunzuma, G. (2017). Secondary School Students' Attitudes towards Their Learning of Geometry: A Survey of Bindura Urban Secondary Schools. International Referred Research Journal, 3(8), 402410.

44. Supandi, T., Luik, M. \& Barron, J. (2018). Role of Mobile Phone Application (MPA) in Mathematics Learning in Indonesia. International Forum of Educational Technology and Society, 20(1), 37-44.

45. Tetzlaff, J. (2017). Using Mobile Phones in Classroom Setting to Enhance Mathematics Achievement. UNLV Thesis, Dissertations, Professional Papers and Capstones. Available at; http://digitalscholarship.unlv.edu/thesisdissertatioons/3015.

46. Uloko, E.S. \& Usman, K.O. (2018). Effect of Ethno-Mathematics Teaching Approach and Interest on Students' Achievement in Locus. Benue Journal of Research in Science and Science Education, 1(1), 81-91.

47. Uwaidiace, I. (2018). WAEC Releases May/June WASSCE Results; This day Newspaper of 20/08/2018. Retrieved from www.allafrica.com.nigeria.nigon 06/05/2018.

48. Vale, C. (2009). Trends and Factors Concerning Gender and Mathematics in AustraliaRetrieved from http://www.faqs.org/periodicalon05/05/2011.

49. Wen-Hung, Ching-Yu, Sheng-Mo \& Rong-Chi (2018). Effects of Game-Based Learning via Mobile Apps in Mathematics Achievement in Taiwan. Journal of Educational Computing Research, 42(3), 36-46.

50. West African Examination Council (2010-2018). Mathematics Chief Examiner's Reports, Lagos: WAEC.

51. Yeng\& Cheng (2019). Impact of Mobile Devices on Students Achievement and Interest in Mathematics. Journal of Physics Conferences Series 983012106.

52. Zeynep, G. (2010). Effects of Using Geometry Software Support by Digital Daily Life Photographs on Geometry Learning. Procedia, Social and Behavioural Sciences 2 (2010), 2824-2828]. 